\title{
CORONARY AND OTHER HEART DISEASE IN A GROUP OF IRISH MALES AGED 65-85
}

\author{
BY \\ ROY M. ACHESON \\ Moyne Institute of Preventive Medicine, Trinity College, Dublin \\ AND \\ E. DONALD ACHESON \\ lately Clinical Tutor, Middlesex Hospital, London
}

In Ireland, as in other countries, the incidence of deaths certified as due to coronary artery disease has increased steadily since the first world war. Thus, in 1955 , over thirty men and thirty women were reported as having died from this cause for every man or woman who had died of the same cause in 1926 (Acheson and Thornton, 1958). In such circumstances it is of some interest to study the morbidity due to the disease; the present paper is the first of a series dealing with various aspects of cardiac function and coronary heart disease in a group of elderly Dubliners who had been skilled or unskilled labourers throughout their working lives.

\section{Materials AND Methods}

The Sample.-The men were pensioners who had been employed by Messrs. Arthur Guinness, Son, and Co. Ltd. in their Dublin Brewery for at least 35 years, and who were aged 65 to 85 years at the time of the study (February-May, 1957). 153 names were selected consisting of all men aged 76 to 85 , and one in five aged 65 to 69 . Their distribution in quinquennial age groups, together with the percentage attendance in each group is shown in Table $I$.

\begin{tabular}{c|c|c|c}
\multicolumn{4}{c}{ TABLE I } \\
\multicolumn{4}{c}{ SAMPLE } \\
\hline $\begin{array}{c}\text { Age Group } \\
\text { (yrs) }\end{array}$ & $\begin{array}{c}\text { Number } \\
\text { Selected }\end{array}$ & $\begin{array}{c}\text { Number } \\
\text { Attended }\end{array}$ & $\begin{array}{c}\text { Per Cent. } \\
\text { Attendance }\end{array}$ \\
\hline $\begin{array}{c}65-69 \\
70-74\end{array}$ & 47 & 43 & 91 \\
$75-79$ & 47 & 42 & 89 \\
$80-85$ & 28 & 21 & 75 \\
\hline Total & 31 & 23 & 74 \\
\hline
\end{tabular}

Of the 24 who failed to attend, seven had died between the time that their names were chosen and the time that the invitations were sent, ten were in-patients in hospital or were otherwise unfit to attend, one had left the country, and six refused to co-operate.

Clinical Examination.-All the men were seen at the Brewery's medical department by one of us (R.M.A.), when a full clinical history was taken, with particular reference to symptoms of cardiovascular disease; notes were also made of habits and past illnesses. A physical examination followed, which included a careful study of the circulatory system and a standard 12-lead electrocardiogram (ECG). Blood pressure was recorded in the recumbent position and the distance between the maximum cardiac impulse and the midline (Wood, 1956) was measured with a linen tape to the nearest quarter inch. With this exception (i.e. locating apex beat), the methods used in conducting the clinical examination conformed as closely as possible with those described by Hunter and Bomford (1956). The men who did not suffer from angina pectoris and in whom no other contraindication to exercise was apparent* were asked to walk backwards and forwards over Master's steps (Master and Oppenheimer, 1926; Master, Friedman, and Dack, 1942), each man wearing terminals on his wrists and ankles, until moderate breathlessness developed. A record was kept of the time taken over the test and of the number of trips made. The subject then lay down on the couch again and was re-connected to the electrocardiograph; between 25 and 30 seconds elapsed between the time that the man had stopped work and the time that the subsequent ECG was commenced. The tracing after exercise was confined to Leads I, II, III, $V_{5}$, and $V_{6}$, which were recorded in series over a period of 5 to 7 minutes. The exercise test was accepted as being adequate if the pulse rate rose

* Contraindications included abnormalities in ECG other than ectopic beats, osteo-arthritis, varicose ulcers, senile debility, etc. 
to over 100 beats per minute (Wood, McGregor, Magidson, and Whittaker, 1950). The number of men who performed adequate tests is shown, by age groups, in Table II.

TABLE II

NUMBER OF MEN IN EACH AGE GROUP WHO PERFOR MED AN ADEQUATE EXERCISE TOLERANCE TEST

\begin{tabular}{c|c|c}
\hline Age Group (yrs) & Number & Per Cent. \\
\hline $65-69$ & 16 & 37 \\
$70-74$ & 19 & 45 \\
$75-79$ & 2 & 9 \\
$80-85$ & 1 & 4 \\
\hline Total & 38 & 29 \\
\hline
\end{tabular}

Interpretation of Electrocardiograms.-The ECG's were all interpreted by one of us (E.D.A.). Initially a report was made on each tracing without recourse to any information about the patient. Some months later the tracings were read again and the two reports were compared and studied in the light of the clinical findings. In view of the problem of observer error (see below) no attempt was made to record minor abnormalities, such as those attributed to coronary heart disease by Evans and McRae (1952).

\section{RESULTS}

Position of THE APEX BeAt.-In the 121 men in whom records were complete and satisfactory in this respect (Fig. 1), the average position of the apex beat was 4.9 inches from the midline. In six of the men ( 5 per cent.) the apex beat was located in the sixth intercostal space, and in them the mean distance from the midline was $5.3 \mathrm{in}$; in one man $(0.8$ per

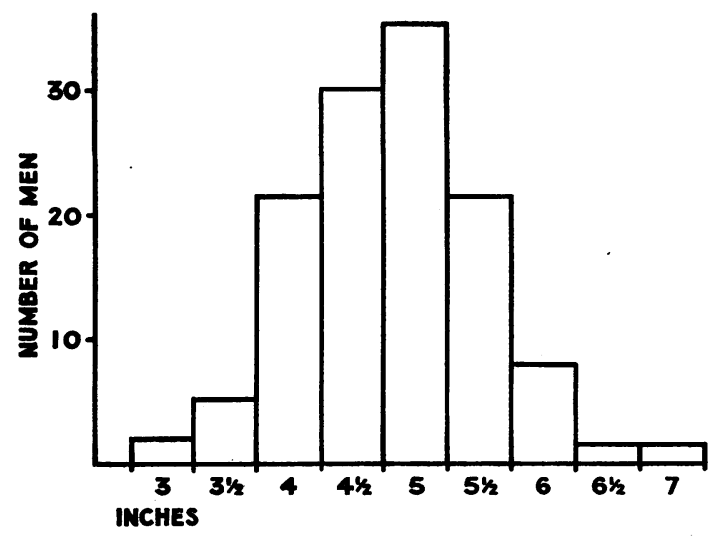

Fig. 1.-Distance of cardiac apex from midline in 121 men aged 65-85 years. cent.) it was located in the fourth intercostal space 4.7 in. from the midline; in the remainder $(94.2$ per cent.) it was located in the fifth intercostal space. (Of the total 129 men, three had a scoliosis sufficient to displace the heart, the apex was impalpable in three, and one had a displaced mediastinum as a consequence of healed tuberculosis.)

Arterial Blood Pressure.-The mean systolic blood pressure (mm. $\mathrm{Hg}$.) for the group was 177.6 and the mean diastolic pressure 97.2. In Fig 2 (opposite) the distribution of the readings is shown for the men aged 65-74 years, and for those aged 75 and over.

There was a slight tendency for diastolic pressure to fall with increasing age, but this did not approach statistical significance $\left(r_{127}=-0.019\right)$.

EXERCISE Tolerance Test.-The amount of work and rate of work done by the men who performed adequate exercise tolerance tests is summarized in Table III.

TABLE III

WORK AND RATE OF WORK CARRIED OUT BY THE MEN WHO PERFORMED AN ADEQUATE EXERCISE TOLERANCE TEST

\begin{tabular}{c|c|c|c|c}
\hline \multirow{2}{*}{ No. of Men } & \multicolumn{2}{|c|}{ Work (ft. lb.) } & \multicolumn{2}{c}{ Rate of work (ft. lb./sec.) } \\
\cline { 2 - 5 } & Mean & S.D. & Mean & S.D. \\
\hline 38 & $4,633 \cdot 2$ & $528 \cdot 0$ & $46 \cdot 7$ & $12 \cdot 8$ \\
\hline
\end{tabular}

Frequency of Coronary Heart Disease.-The reasons for believing that 53 (41 per cent.) of the men suffered from definite or doubtful coronary heart disease are shown in Table IV (opposite).

Of 24 men with definite cardiac pain, eight had normal and seventeen abnormal ECG's at rest. Three of those whose ECGs were abnormal showed classical signs of myocardial infarcation, ten showed non-specific changes involving the RST segment and $\mathrm{T}$ wave, two had complete right bundle branch block, and two were in auricular fibrillation. The six men with doubtful angina pectoris included in Table IV had abnormal tracings; one had an anterior myocardial infarcation, one a complete and one an incomplete right bundle branch block, and four had abnormalities of RST segment and T wave.

Abnormal ECGs with no history of cardiac pain were found in 22 additional patients; one of these had the classical signs of anterior myocardial infarction, and in the remaining 21 the changes were non-specific and it was difficult to be certain to what extent coronary heart disease was responsible for 
S Y S TOLIC

DI ASTOLIC

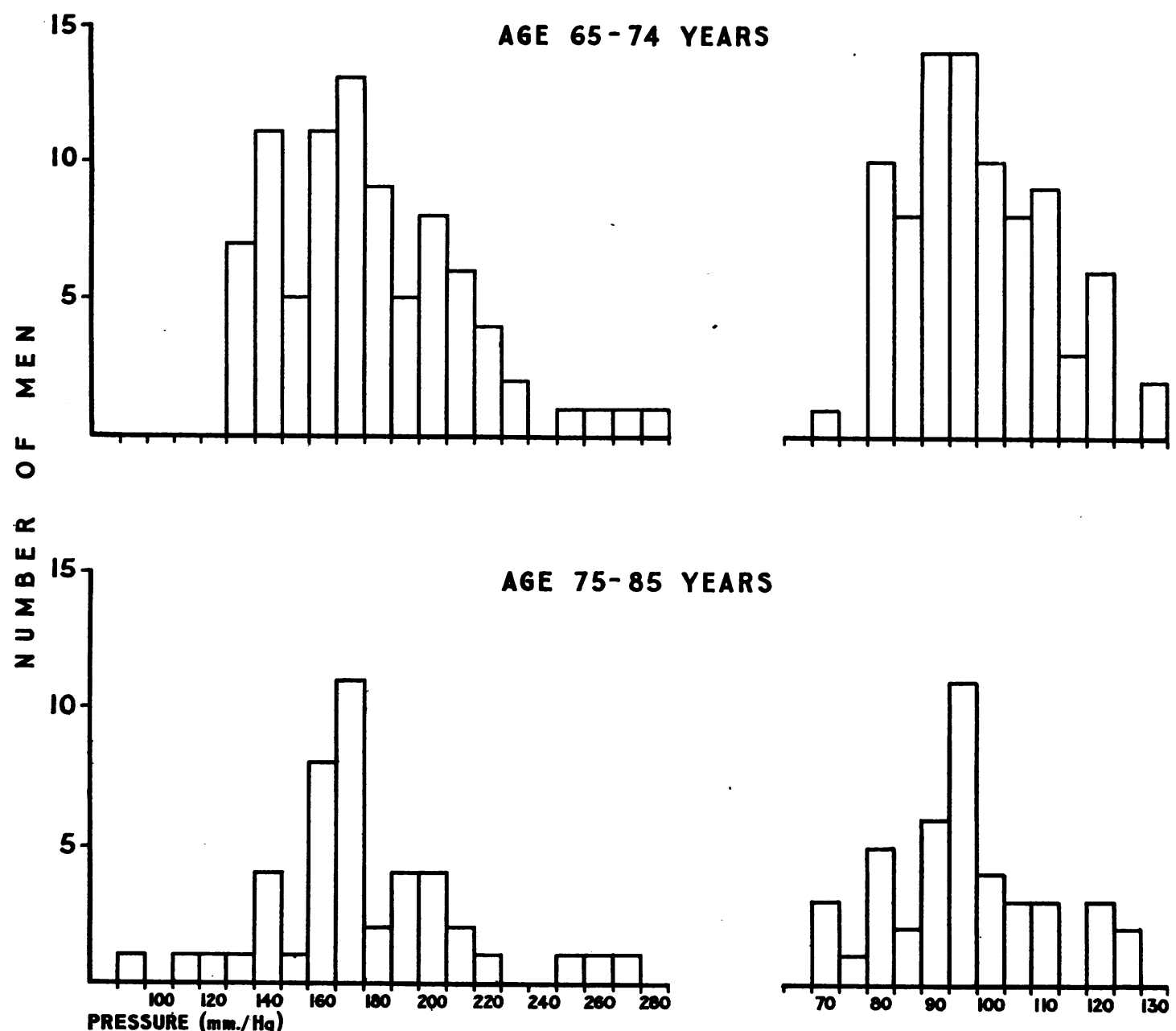

FIG. 2.-Systolic and diastolic blood pressure in 85 men aged 65-74 yrs and 43 men aged 75-85 yrs.

TABLE IV

CRITERIA FOR DIAGNOSIS OF CORONARY HEART DISEASE IN 53 MEN

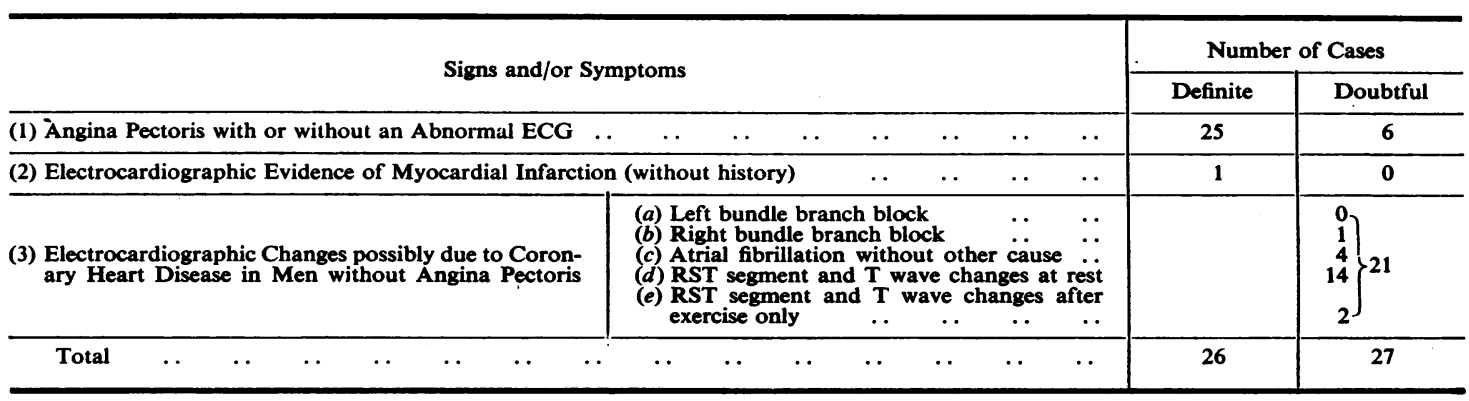


them, particularly as hypertension and clinical evidence of left ventricular enlargement were frequently present also (Table V). In fourteen cases the changes present affected predominantly the RST segment and $T$ wave in left ventricular leads. When the first study was made without knowledge of the subjects' symptoms, the tracings were classified as either "left ventricular hypertrophy" or "ischaemic" patterns. However, the second study, made after an interval and in the light of the symptoms, was most illuminating, for not only did it show that there was a poor relationship between the electrocardiographic diagnosis of these conditions and the clinical facts, but also that the observer could not be sure of repeating his results; thus tracings classified as "ischaemic" on the first occasion were often read as "left ventricular hypertrophy" on the second, and vice versa. In view of this unsatisfactory state of affairs, it was decided to place in a single group in Table IV all the men who gave no history of cardiac pain but had RST segment depression of $1.0 \mathrm{~mm}$. or more, or $T$ wave inversion, or both, in left ventricular leads (in the absence of pathological Q waves). It is reasonable to suppose that coronary artery disease played a part in the production of these changes in some cases. In two further men, neither of whom gave a history of cardiac pain, the resting ECG was normal but exercise produced flat or sagging depression of the RST segment of at least $1.00 \mathrm{~mm}$. As these changes were similar to those found after exercise in sufferers from angina pectoris with normal resting ECGs (Wood and others, 1950); the two men were also grouped among the cases of doubtful coronary heart disease.

The distribution into age groups of the 53 men diagnosed as having definite or doubtful coronary heart disease is shown in Table VI. Sixteen men (13 per cent.) were classified as having no evidence of coronary heart disease; these were men who had a normal ECG before and after an adequate exercise test, and who had never experienced angina pectoris.

TABLE VI

FREQUENCY OF CORONARY HEART DISEASE

\begin{tabular}{|c|c|c|c|c|c|c|}
\hline \multirow{3}{*}{$\begin{array}{c}\text { Age } \\
\text { Group } \\
\text { (yrs) }\end{array}$} & \multicolumn{4}{|c|}{ Coronary Heart Disease } & \multirow{2}{*}{\multicolumn{2}{|c|}{ Indeterminate }} \\
\hline & \multicolumn{2}{|c|}{$\begin{array}{l}\text { Definite or } \\
\text { Doubtful }\end{array}$} & \multicolumn{2}{|c|}{ Not Detectable } & & \\
\hline & No. & Per Cent. & No. & Per Cent. & No. & Per Cent. \\
\hline $65-69$ & 18 & 42 & 9 & 21 & 16 & 37 \\
\hline $70-74$ & 14 & 33 & 7 & 17 & 21 & 50 \\
\hline $75-79$ & 9 & 43 & 0 & $\mathbf{0}$ & 12 & 57 \\
\hline $80-85$ & 12 & 52 & 1 & 4 & 10 & 43 \\
\hline $\begin{array}{l}\text { Whole } \\
\text { Sample }\end{array}$ & 53 & 41 & 17 & 13 & 59 & 46 \\
\hline
\end{tabular}

The diagnosis was considered to be "indeterminate" $\delta$ " (44 per cent.) in those:

(1) who were unfit to perform the exercise test for reasons other than angina pectoris,

(2) whose exercise test was considered to be inadequate,

TABLE V

OBSERVATIONS IN 21 MEN IN WHOM THE DIAGNOSIS OF "PROBABLE” CORONARY HEART DISEASE RESTED UPON NONSPECIFIC ECG CHANGES

\begin{tabular}{|c|c|c|c|c|c|}
\hline \multirow{2}{*}{ Case No. } & \multirow{2}{*}{ Age (yrs) } & \multicolumn{2}{|c|}{ Blood Pressure $(\mathrm{mm} . / \mathrm{Hg})$} & \multirow{2}{*}{$\begin{array}{l}\text { Distance from Midline } \\
\text { of Cardiac Apex (in.) }\end{array}$} & \multirow{2}{*}{$\begin{array}{l}\text { ECG* Diagnosis on } \\
\text { Second Reading }\end{array}$} \\
\hline & & Systolic & Diastolic & & \\
\hline $\begin{array}{r}2 \\
9 \\
18 \\
22 \\
44 \\
46 \\
50 \\
53 \\
54 \\
62 \\
64 \\
65 \\
83 \\
84 \\
90 \\
101 \\
103 \\
111 \\
119 \\
128 \\
129\end{array}$ & $\begin{array}{l}65 \\
67 \\
69 \\
70 \\
68 \\
68 \\
80 \\
81 \\
81 \\
82 \\
82 \\
82 \\
71 \\
72 \\
70 \\
66 \\
65 \\
73 \\
77 \\
79 \\
85\end{array}$ & $\begin{array}{l}140 \\
200 \\
135 \\
155 \\
190 \\
200 \\
270 \\
210 \\
190 \\
140 \\
170 \\
170 \\
175 \\
205 \\
270 \\
180 \\
145 \\
210 \\
150 \\
200 \\
120\end{array}$ & $\begin{array}{r}80 \\
110 \\
80 \\
80 \\
95 \\
110 \\
120 \\
120 \\
100 \\
100 \\
90 \\
105 \\
100 \\
90 \\
115 \\
105 \\
95 \\
100 \\
85 \\
90 \\
80\end{array}$ & $\begin{array}{l}4 \frac{1}{2} \\
5 \frac{1}{2} \\
4 \\
3 \frac{3}{4} \\
4 \frac{3}{4} \\
4 \frac{1}{2} \\
5 \frac{1}{2} \\
5 \frac{1}{2} \\
5 \\
5 \\
5 \frac{1}{2} \\
5 \\
5 \frac{1}{4} \\
5 \frac{3}{4} \\
5 \frac{1}{1} \\
5 \frac{1}{2} \\
4 \frac{1}{41} \\
55 \\
5 \\
5 \frac{1}{2}\end{array}$ & $\begin{array}{c}\text { M.I. } \\
\text { M.I. } \\
\text { M.I.(a.e.) } \\
\text { L.V.H. } \\
\text { M.I.(a.e.) } \\
\text { M.I. } \\
\text { M.I. } \\
\text { L.V.H.H. } \\
\text { M.I. } \\
\text { L.V.H. } \\
\text { Fibrillation and L.V.H. } \\
\text { L.V.H. } \\
\text { Fibrillation and M.I. } \\
\text { L.V.H. } \\
\text { L.V.H. } \\
\text { R.B.B.B. } \\
\text { Fibrillation } \\
\text { M.I. } \\
\text { Fibrillation } \\
\text { M.I. } \\
\text { L.V.H. }\end{array}$ \\
\hline
\end{tabular}

* L.V.H. $=$ Left ventricular hypertrophy. M.I. $=$ Myocardial ischaemia. R.B.B.B. $=$ Complete right bundle branch block. (a.e.) $=$ after exercise 
(3) whose ECG, before or after exercise, showed abnormalities other than those listed above (further details of this group are given in Table VII).

TABLE VII

A FURTHER ANALYSIS OF THE 59 MEN IN WHOM THE DIAGNOSIS WAS CLASSED AS "INDETERMINATE" IN TABLE VI

\begin{tabular}{|c|c|c|}
\hline \multicolumn{2}{|c|}{ Observation } & $\begin{array}{l}\text { No. of } \\
\text { Cases }\end{array}$ \\
\hline \multicolumn{2}{|c|}{$\begin{array}{l}\text { Performed an exercise test, but failed to raise the pulse } \\
\text { rate to } 100 / \mathrm{min} . \\
\end{array}$} & 11 \\
\hline $\begin{array}{l}\text { Performed an adequate } \\
\text { exercise test, but had } \\
\text { the following abnor- } \\
\text { malities in the ECG: }\end{array}$ & 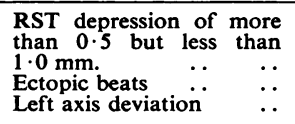 & $\left.\begin{array}{r}2 \\
11\end{array}\right\}^{14}$ \\
\hline \multicolumn{2}{|c|}{ 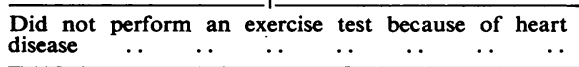 } & 6 \\
\hline \multicolumn{2}{|c|}{$\begin{array}{l}\text { Did not perform an exercise test for reasons not con- } \\
\text { nected with the heart } \quad \ldots \\
\end{array}$} & 25 \\
\hline \multicolumn{2}{|c|}{ Imperfect or Inadequate ECG ... } & 3 \\
\hline Total & .. & 59 \\
\hline
\end{tabular}

Despite the fact that 33 of the men with coronary heart disease admitted to symptoms, only twelve (9.3 per cent.) had consulted their doctor for treatment of the condition before the survey (see Table VIII).

TABLE VIII

MEN WITH SYMPTOMS OF CORONARY HEART DISEASE WHO HAD, OR HAD NOT, CONSULTED THEIR DOCTOR

\begin{tabular}{l|c|c|c}
\hline \multicolumn{1}{c|}{ Symptom } & $\begin{array}{c}\text { Had } \\
\text { Consulted } \\
\text { Doctor }\end{array}$ & $\begin{array}{c}\text { Had Not } \\
\text { Consulted } \\
\text { Doctor }\end{array}$ & Total \\
\hline Definite Angina Pectoris & 9 & 16 & 25 \\
\hline Doubtful Angina Pectoris & 1 & 5 & 6 \\
\hline $\begin{array}{l}\text { Symptoms of Cardiac } \\
\text { Failure without Angina } \\
\text { Pectoris (atrial fibrillation) }\end{array}$ & 2 & 0 & 2 \\
\hline \multicolumn{1}{c|}{ Total } & 12 & 21 & 33 \\
\hline
\end{tabular}

\section{Other Heart Disease}

(i) Degenerative Disease of the Aortic Valve.Ten men (8 per cent.) had clinical evidence of stenosis and/or incompetence of the aortic valve; one of these also had angina pectoris together with ECG changes in the RST segment and is included in Table IV. Six of the remaining nine had a systolic blood pressure of over $200 \mathrm{~mm}$. $\mathrm{Hg}$, and five of these a diastolic blood pressure of $100 \mathrm{~mm}$. $\mathrm{Hg}$ or more. None of the men with aortic valve lesions had a diastolic pressure of less than $90 \mathrm{~mm}$. $\mathrm{Hg}$. (ii) Rheumatic Heart Disease.-Three men (2 per cent.) had rheumatic heart disease.

(iii) Cardiac Failure.-Four men (3 per cent.) were in congestive heart failure with engorgement of the veins of the neck. One complained of angina pectoris and had atrial fibrillation; two others also had atrial fibrillation and in the absence of valvular disease or thyrotoxicosis it was assumed that this was caused by coronary heart disease, thus they are included in Group 3 in Table IV. The fourth man in congestive heart failure had mitral stenosis. Three other men ( 2 per cent), all of whom had coronary heart disease, gave a history of paroxysmal nocturnal dyspnoea.

There was little severe chronic bronchitis, and none of the men had cor pulmonale.

(iv) Syphilitic and Congenital Heart Disease.-As far as we could ascertain, only one man had ever had a positive Wassermann reaction, and he showed no evidence that syphilis had caused cardio-vascular disease. None of the men had congenital heart disease.

\section{Discussion}

Our data show that, in a small group of elderly Dubliners, the frequency of definite coronary disease is 20 per cent., the diagnosis being based upon a history of cardiac pain or the classical ECG signs of myocardial infarction in the absence of such a history. In a further 21 per cent., non-specific electrocardiographic signs were interpreted as being due, in part at least, to coronary heart disease. The men are drawn from one social stratum and obviously, therefore, are not representative of the elderly male population of the city; moreover, since Messrs. Guinness have, for about 80 years, subjected their employees to a rigorous physical examination before recruiting them, these men cannot considered a typical sample of the skilled and unskilled labourers in the community. It is, nevertheless, of some interest to compare the frequency of coronary heart disease observed in our sample with frequencies in some other recent reports.

The conduct of the research in each of the previous inquiries differs from that of our inquiry in at least one respect. For example, Sheldon (1948) and Droller and Pemberton (1953) studied people of more or less equivalent age, but included women and saw the patients in their own homes. Sheldon (1948), who did not carry out a physical examination, found the eleven out of $477(2 \cdot 3$ per cent.) old people in Wolverhampton complained of angina pectoris despite the fact that he asked no direct question about this symptom, and a further three 
had had a coronary thrombosis. An additional, 9.4 per cent. of his sample had, at some time, received treatment for high blood pressure, and a further 5 per cent. for heart disease, the nature of which was unknown. Droller and Pemberton (1953) carried out a physical examination in their study of elderly folk in Sheffield, but did not use the electrocardiograph; 20.5 per cent. of their sample of 476 gave a history of angina in response to direct questioning and the distribution was equal in the two sexes. Thus, while no exact comparison can be made between Sheldon's survey and ours, the frequency of angina in the Sheffield study is very similar to that in the Dublin pensioners.

Brown, Davidson, McKeown, and Whitfield (1957) depended upon the co-operation of general practitioners for a survey of cardiovascular disease in 1,062 men aged 60 to 69 years in Birmingham. The practitioners attempted to interview and examine all the men on their lists in the age range which was being studied, and referred those cases which had signs or syptoms suggestive of coronary heart disease to the University Hospital where they were seen by a consultant physician. Confirmation of the diagnosis was established on ECG or other grounds in 8.4 per cent. of the entire sample; only 5.9 per cent. of the sample had angina pectoris however. Even if allowance is made for the fact that these men are in general younger, the frequency either of definite coronary heart disease or angina pectoris is very much lower than that in the Sheffield or the present study. However, only $9 \cdot 3$ per cent. of our sample has sought treatment for their coronary heart disease, of their own volition, before the survey.

To our knowledge, apart from our own survey, electrocardiography has been used to screen an entire sample only in men aged under 65 . Thus, Thomas, Cotes, and Higgins (1956) diagnosed coronary heart disease in 38 per cent. of a random sample of 47 coal-miners in South Wales; they published the ECGs and some of them would have been classed as "doubtful" rather than "definite" on our rating. Eight (17 per cent.) of their sample complained of angina pectoris (Thomas, Cotes, and Higgins, personal communication), however, so the prevalence of this symptom in their community is similar to the figures for Sheffield and Dublin. If in our series the cases of doubtful and definite coronary heart disease are combined, the frequency rises to 41 per cent., which is again comparable with the Welsh figure.

Electrocardiography has also been used for screening in America, but the men studied there have been younger and the reported frequency of coronary heart disease lower. For instance, Doyle, Heslin,
Hilleboe, Formel, and Korns (1957), using an exercise test in addition to clinical assessment and a resting ECG, found a frequency of $7 \cdot 1$ per cent. in a sample of 481 male clerks aged 50-55 years, and Dawber, Moore, and Mann (1957), who did not employ an exercise test, diagnosed coronary heart disease in 9.6 per cent. of a sample of the male inhabitants of Framingham, Massachusetts, aged 55-62 years.

In conclusion, if allowance is made for differences in technique, our estimate of frequency of coronary heart disease in a small group of elderly Dubliners bears close comparison with those for Sheffield (Droller and Pemberton, 1953) and South Wales (Thomas, Cotes, and Higgins 1956) but is much higher than that given in the report from Birmingham by Brown and others (1957). American surveys in which comparable techniques have been used were carried out on younger men.

\section{SUMMARY}

A sample of 129 of the pensioners aged 65-85 years on the list of Messrs. Arthur Guinness, Son, and Co. Ltd. (Dublin) were interviewed and examined physically. Values are given for the distance of the cardiac apex from the midline, and for the arterial blood pressure. On the basis of angina pectoris together with an ECG taken before and after exercise, 26 (20 per cent.) were diagnosed as suffering from definite and 27 ( 21 per cent.) from probable coronary heart disease; the number of subjects suffering from other forms of heart disease is also recorded. Only $9 \cdot 3$ per cent. of the sample had sought treatment for coronary heart disease before the survey. These findings are compared with those of similar studies elsewhere.

We are grateful to the board of directors of Messrs. Arthur Guinness, Son, and Co., Ltd. (Dublin) and to their chief medical officer, Dr. Brian Pringle, both for allowing us to carry out this study and for generously providing us with the necessary accomodation, materials, and technical staff. The quality of the Company's records, which date back over half a century, has added enormously to the value of our data. We would also like to thank Dr. Jack Eustace, Prof. W. J. E. Jessop, and the many other people who have advised and assisted the work.

\section{REFERENCE}

Acheson, R. M., and Thornton, E. H. (1958). Brit. J. Prev. Soc. Med., 12, 82.

Brown, R. G., Davidson, L. A. G., Mckeown, T., and Whitfield, A. G. W. (1957). Lancet, 2, 1073.

Dawber, T. R., Moore, F. E., and Mann, G. V. (1957). Amer. J. Publ. Hith, 47, No. 4, Pt 2 (April), p. 4. 
Doyle, J. T. Heslin, A. S., Hillboe, H. E., Formel, P. F., and Korns, R. F. (1957). Ibid., 47, No. 4, Pt 2 (April), p. 25.

Droller, H., and Pemberton, J. (1953). Brit. Heart J., 15, 199.

Evans, W., and McRae, C. (1952). Ibid., 14, 429.

Hunter, D.; and Bomford, R. R. (1956). "Hutchinson's Clinical Methods;, 13th ed. Cassell, London.

Master, A. M., Friedman, R., and Dack, S. (1942). Amer. Heart J., 24, 777.

- and Oppenheimer, E. T. (1929). Amer. J. med. sci., 177, 223.
Sheldon, J. H. (1948). "The Social Medicine of Old Age". Oxford University Press, London.

Thomas, A. J., Cochrane, A. L., and Higgins, I. T. T. (1958). Lancet, 2, (in the press).

- Cotes, J. E., and Higgins, I. T. T. (1956). Ibid., 1, 414.

Wood, P. (1956). "Diseases of the Heart and Circulation", 2nd ed. Eyre and Spottiswoode, London. Brit. Heart J., 12, 363.

\section{ADDENDUM}

Since this paper went to press a further prevalence study has been completed in Wales by Thomas, Cochrane, and Higgins (1958), who found that in the opinion of three independent assessors 17 per cent. of a random sample of $\mathbf{8 5}$ agricultural workers aged
55-64 had electrocardiographic evidence of coronary heart disease; when patients with symptoms were included the overall prevalence in this sample was $21 \cdot 3$ per cent. 